\title{
SARS-CoV-2 Remained Airborne for a Prolonged Time in a Lockdown Confined Space
}

Aerosol and Air Quality Research

\section{OPEN ACCESS}

Received: June 8, 2021

Revised: January 9, 2022

Accepted: January 13, 2022

\section{${ }^{*}$ Corresponding Authors:}

Maosheng Yao

yao@pku.edu.cn

Quanyi Wang

bjcdcxm@126.com

${ }^{\dagger}$ These authors contributed equally to this work

\section{Publisher:}

Taiwan Association for Aerosol Research

ISSN: $1680-8584$ print ISSN: 2071-1409 online

(c) Copyright: The Author(s). This is an open access article distributed under the terms of the Creative Commons Attribution License (CC BY 4.0), which permits unrestricted use, distribution, and reproduction in any medium, provided the original author and source are cited.

\author{
Xinyue $\mathrm{Li}^{{ }^{+\dagger}}$, Xiao $\mathrm{Qi}^{2+}$, Jianxin $\mathrm{Ma}^{2+}$, Yang $\mathrm{Pan}^{3+}$, Tian Tian ${ }^{2}$, Yue Zhang ${ }^{2}$, \\ Zhen $\mathrm{Li}^{2}$, Wenjing $\mathrm{Li}^{2}$, Lingli Sun ${ }^{2}$, Lu Zhang ${ }^{1}$, Zheng Zhang², Quanyi Wang ${ }^{3 *}$, \\ Maosheng $\mathrm{Yao}^{1 *+}$
}

\begin{abstract}
${ }^{1}$ State Key Joint Laboratory of Environmental Simulation and Pollution Control, College of Environmental Sciences and Engineering, Peking University, Beijing, China

${ }^{2}$ Center for Disease Control and Prevention of Chaoyang District of Beijing, Beijing, China

${ }^{3}$ Beijing Center for Disease Prevention and Control, Beijing Research Center for Preventive Medicine, Beijing, China
\end{abstract}

\section{ABSTRACT}

Airborne transmission of COVID-19 plays an important role for the pandemic. However, nucleic acid based evidence of direct association of COVID-19 with environmental contamination is lacking. Here, we investigated a COVID-19 outbreak with two fast food employees infected, in which a traveler despite of a 14-day quarantine turned positive after check in with a hotel, using environmental SARS-CoV-2 sampling, epidemiological tracing, viral RNA sequence as well as surveillance method. Out of 25 positive environmental air and surface swab samples $(\mathrm{N}=237)$ collected, SARS-CoV-2 was found to have remained airborne (5640-7840 RNA copies $\mathrm{m}^{-3}$ ) for more than 4 days in a female washroom. After aging for 5 days in the air, no viable virus was detected. The traveler did not have any contacts with the two employees; however, genome sequencing showed that SARS-CoV-2 variants from three patients and two environmental surface samples belonged to $20 \mathrm{~B}$ viral clade, sharing a nucleic acid identity of more than $99.9 \%$. We concluded that the outbreak was triggered by SARS-CoV-2 contaminated environments, where the employees inhaled the virus from the air or touching facility surfaces where the traveler did not have any physical contacts with.

Keywords: COVID-19, Airborne transmission, Environmental transmission, Genetic evidences

\section{INTRODUCTION}

The COVID-19 pandemic has continued for more than one year, and it seems not to end soon. Global efforts have been made in place for controlling the outbreak and environmental transmission is extensively studied (Morawska et al., 2021). Previously, SARS-CoV-2 was detected in air, floor samples and surface swabs (Ong et al., 2020; Guo et al., 2020; Santarpia et al., 2020; Liu et al., 2020). Another study showed that COVID-19 patients in their earlier disease stages could emit millions of SARS-CoV-2 per hour (Ma et al., 2020). In addition, infectious SARS-CoV-2 was detected from hospital air (Lednicky et al., 2020). Epidemiological investigations show that in semi-enclosed spaces such as tour ships, social gathering venues, and buses aerosol transmission of COVID-19 is highly plausible (Azimi et al., 2021; Miller et al., 2020; Shen et al., 2020). Increasing volumes of evidences suggest that aerosol played an important role in the COVID-19 transmission (Prather et al., 2020a, b). Multinational health organizations, including the World Health Organization has officially recognized the airborne transmission route for COVID-19 (WHO, 2021; CDC US, 2021; CDC CN, 2020). Environmental transmission evidences for COVID-19 are accumulating very fast. However, nucleic acid based evidence of direct link of COVID-19 to environmental contamination is lacking. Here, we report an environmental transmission with both nucleic acid sequence and epidemiological evidences for an outbreak of COVID-19 in a chain hotel employee building in Beijing. 


\section{MATERIALS AND METHODS}

\subsection{Descriptions of COVID-19 Patients and Epidemiological Tracing}

In this work, only three COVID-19 patients were involved. Epidemiological tracing was performed for all three confirmed COVID-19 patients involved and their close contacts. Epidemiological tracing involved the questionnaire of time-resolved itinerary and activities for people who were potentially involved during the outbreak. In addition, the epidemiological tracing also used the cell-phone location data and surveillance to further confirm the itinerary. A traveler from Hong Kong, the index COVID-19 patient, was discharged on the morning of Dec. 12, 2020 after a 14-day quarantine in Changping District of Beijing, and later checked in a chain hotel located in Chaoyang District of Beijing (Fig. S1). On the evening of Dec. 13, 2020, the traveler developed a fever according to him and went to a hospital in Beijing for examination next morning. The traveler was confirmed to be infected by SARS-CoV-2 on Dec. 14, 2020, and was quarantined immediately. The hotel was locked down on Dec. 14, 2020. Among the chain hotel (Company A) staffs, two cleaners had cleaned the traveler's rooms. One (Cleaner A) residing in Room \#5 (Fig. 1(A)) was responsible for cleaning the bed, while the other (Cleaner B) residing in Room \#8 was responsible for cleaning the toilet. The cleaners would dump the hotel room garbage through the employee building stairs. All employees $(n=37)$ (at the time of the outbreak there were about 20 people) from four different companies (A-D) (Fig. 1(A)) residing in the same employee residence building share the same public toilet, washroom and bath rooms reserved for female and male, respectively (Fig. 1(A)). Some of these employees have other places to live in Beijing and do not spend the nights in the employee building. All rooms in the employee building do not have toilets inside. During the outbreak, there were two employees at one time residing in Room \#10 from Company B (a fast food provider) next to the hotel were confirmed to be infected with SARS-CoV-2 on Dec. 17 and 18 , respectively, and later transported to a local hospital for treatment on their diagnosis day. In addition, surveillance video was also obtained through the assistance of the police authority in Chaoyang District of Beijing. All involved human subjects were screened for COVID-19, and relevant long process was waived for ethics approval due to urgency of the investigation and also the non-invasive exhale breath collection by Chaoyang CDC Ethics Committee.

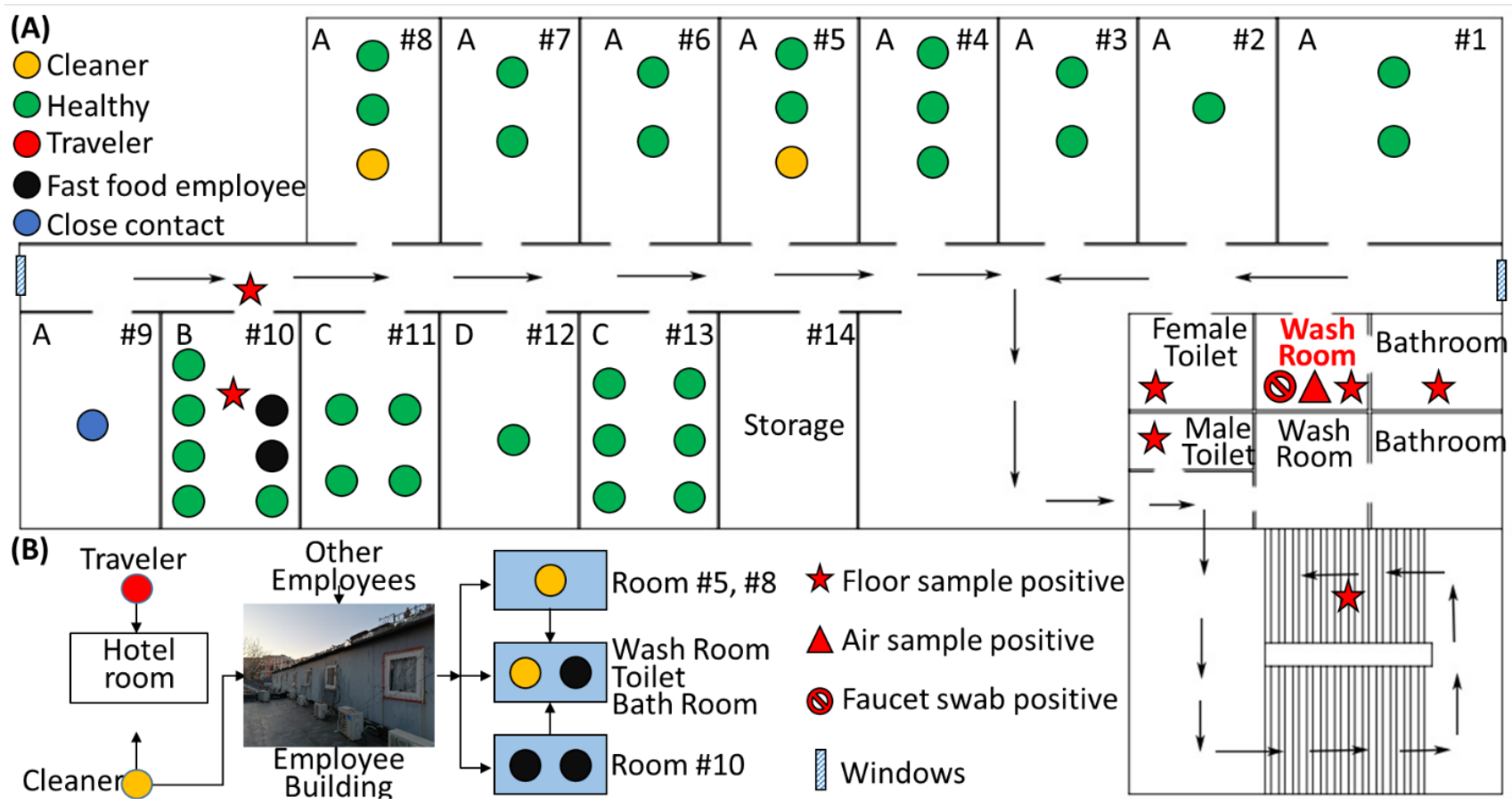

Fig. 1. Map of the employee building (A) with SARS-CoV-2 positive locations and samples and (B) an illustration of the COVID-19 transmission route from the traveler to the two COVID-19 confirmed fast food employees. The temperature, humidity, size dimensions for rooms, washrooms, and toilets are shown in Table S1. 


\subsection{Air Sample Collection}

Air samples were taken from employee building from different sampling locations: the corridor, the employee rooms, washroom, toilets, etc. as shown in Table S2. The employee building only has two windows at each end of the corridor. The air samples were collected into $3 \mathrm{~mL}$ virus culture liquid (MT0301) (Yocon Biology Inc., Beijing, China) using one cyclone impinger developed by Peking University and commercialized by a company in Beijing (Fig. S2) as reported in another work (Li et al., 2021). The sampler was used in the SARS-CoV-2 aerosol monitoring in Wuhan in Feb-March 2020, and it was shown capable of detecting 9-219 viral RNA $\mathrm{m}^{-3}$ when combined with digital PCR method (Zhou et al., 2021). Use of mineral oil could help preserve the integrity of viral particles with less evaporation, but it involves subsequent viral particle extraction step for PCR test. Additionally, mineral oil does not inactivate the virus. The viral culture chosen would inactive SARs-CoV-2 during the sampling process, and it is also suitable for PCR analysis immediately. In addition, the sampler was also assisted by a robot, and operated at a $400 \mathrm{~L} \mathrm{~min}^{-1}$ flow rate in the corridor space (Video S1). After each 40 minutes' sampling, 1.5-2 mL collection liquid remained due to the liquid evaporation. The collected air samples were transported to the Chaoyang CDC BSL-2 laboratory for SARS-CoV-2 analysis on the same day. A total of 20 air samples were obtained (Table S2).

\subsection{Surface Swab Sample Collection}

The surfaces ( 10 or $25 \mathrm{~cm}^{2}$ ) of objects and floors in the employee building or personal items from two confirmed COVID-19 patients were scrubbed using a wet cotton swab. The standard wet-cotton-swab protocol is used by Chinese CDCs and was used in our SARs-CoV-2 monitoring in Wuhan during Feb-March 2020 (Zhou et al., 2021). Upon the collection, surface swab samples were immediately deposited into a $3 \mathrm{~mL}$ virus collection liquid to inactivate and extract viral particles (Yocon Biology, Inc.), and further delivered to the Chaoyang CDC laboratory for SARS-CoV-2 analysis on the same day. A total of 193 surface swabs were obtained (Table S2).

\subsection{SARS-CoV-2 Analysis Using Reverse Transcription Polymerase Chain Reaction (RT-PCR)}

For all collected samples, several steps were carried out for SARS-CoV-2 analysis. First, a $200 \mu \mathrm{L}$ sample liquid was used to extract SARS-CoV-2 RNA using a MagMAX ${ }^{\text {TM }}$ Multi-Sample 96-Well RNA Isolation Kit (Thermo Fisher Scientific, Waltham, MA) according to the manufacturer's instructions. The final solution volume from the above extraction procedure was 20-30 $\mu \mathrm{L}$. Then, detection of SARS-CoV-2 targeting both ORF1ab and N genes using a detection kit (Daan Gen Co., Ltd. of Sun Yat-sen University) were performed by RT-PCR (Roche 96 fluorescence qPCR instrument, Roche Molecular Systems, Inc., Pleasanton, CA) under the following cycle conditions: $50^{\circ} \mathrm{C}$ for $15 \mathrm{~min}$, and $95^{\circ} \mathrm{C}$ for $15 \mathrm{~min}$, followed by 45 cycles of $94^{\circ} \mathrm{C}$ for $15 \mathrm{~s}$, and $55^{\circ} \mathrm{C}$ for $45 \mathrm{~s}$. The reaction mixture included $17 \mu \mathrm{L}$ of nucleic acid amplification mix, SARS-CoV-2 reaction mix, RNA free $\mathrm{H}_{2} \mathrm{O}$, $3 \mu \mathrm{L}$ Taq EnzymeMix, and $5 \mu \mathrm{L}$ of sample. DI water was used as a negative control. In accordance with the detection kit's instructions, samples with Ct values of less than 40 for both ORF1ab and $\mathrm{N}$ genes or at least for one gene confirmed can be treated as positive for SARS-CoV-2. According to the kit, the detection limit is 500 copies $\mathrm{mL}^{-1}$. SARS-CoV-2 levels are estimated assuming an amplification efficiency of $75 \%$ based on the cycle threshold value for each sample. For all samplings, one-time-use consumables were used, while DI water served as negative controls. All SARS-CoV-2 analyses for the samples were performed in a BSL-2 Laboratory by Chaoyang CDC.

\subsection{Next Generation Sequencing}

Viral RNA was extracted from three patients' nasopharyngeal /oropharyngeal samples and two surface swab samples using automated nucleic acid purification (KingFisher ${ }^{\mathrm{TM}}$ Flex Purification System, Thermo, USA). First strand cDNA synthesis was performed using $8 \mu \mathrm{L}$ input RNA and random hexamers with the SuperScript IV First Strand Synthesis System (Invitrogen, Waltham, MA, USA). Then, tiled-PCR amplicons were generated by 25-32 PCR cycles using the ARTIC nCoV-2019 sequencing protocol v3 (https://www.protocols.io/view/ncov-2019-sequencing-protocol-v3). The primers for Pool 1 and 2 were synthesized by Sangon (China). Next Generation Sequence libraries were prepared by Nextera XT Library Prep Kit (Illumina, San Diego, CA, USA) and sequenced on 
MiniSeq using $2 \times 150$ paired-end sequencing kits (Illumina, San Diego, CA, USA). Negative control samples were processed and sequenced in parallel for each sequencing run as a quality control. The sequences of the SARS-CoV-2 isolated from the traveler and two secondary COVID-19 cases were deposited to GISAID database with their IDs (EPI_ISL_1117378, EPI_ISL_1117376, and EPI_ISL_1117377, respectively). The two environmental samples' (surface swabs from quilt of Room\#10- B1701005, and female toilet floor- B1701010 (Table S1-12-17-2) accession numbers are EPI_ISL_1168770 and EPI_ISL_1168771, respectively.

\subsection{SARS-CoV-2 Genome Analysis}

Quality control and adaptor trimming was done by CLC Genomics Workbench (v10.0, Qiagen, Germany). The clean reads were mapped to the reference SARS-CoV-2 genome (GenBank: MN908947.3) using Bowtie2 (Ong et al., 2020) and SAMtools (Guo et al., 2020). Variant calling was performed using Genome Analysis Toolkit (GATK, version 4.0.10). Phylogenetic analysis was conducted using MAFFT v7 (Santarpia et al., 2020). A maximum likelihood tree was inferred by NJ model with bootstrap of 1000 , including the patients' SARS-CoV-2 genomes, the reference genome sequence and 207 representative genomes selected from NCBI virus database by regions and clades of interest. The final figure was made using iTOl (https://itol.embl.de/).

\subsection{SARS-CoV-2 Culturing}

In order to study the viability of SARS-CoV-2, additional three air samples were collected from the female washroom on Dec 22 as described above, and further virus culturing was conducted. The virus cultivability was conducted by the Chinese Center for Disease Control and Prevention. Air samples collected were mixed with 3-5 $\times 10^{4}$ Vero cells (WHO (ECACC)) and then distributed in 96 -well culture plates. The plates were cultured in a $5 \% \mathrm{CO}_{2}$ incubator at $37^{\circ} \mathrm{C}$ for 4 days in a BSL-3 Laboratory, and cells were then checked for the presence of a cytopathogenic efficiency (CPE) under a microscope. If no CPE was observed, the sample was described not to have a viable SARS-CoV-2.

\section{RESULTS AND DISCUSSION}

Epidemiological tracing revealed that these two fast food employees and also those two cleaners used the same toilet, washroom and also bathroom during the outbreak time period. In the washroom, there is a washing machine that was used by the cleaners to wash the hotel uniforms. Surveillance video also reveals that one of the cleaners entered the employee building about 1 minute after two confirmed COVID-19 staying in Room \#10 did around 9:00 PM on Dec. 13, 2020 (Fig. S2) through the employee building stairs. The hotel employee staying in Room \#9, free from SARS-CoV-2 infection, had a brief conversation (a close contact) with the traveler who wore a mask at the time. The cleaners did not know the two confirmed fast food employees from Company B. During the screening campaign, the two hotel cleaners were both tested negative for COVID-19. Disinfections were carried out for both employee building and the hotel on Dec. 17, 2020 and finished on at 2:30 AM of Dec. 18, 2020.

In response to the outbreak, we collected a total of 237 environmental samples including air, floor and surface swab from hotel, the employee building and also Company B as listed in Table 1 on Dec. 17, 20, and 21 (Table S2 Supporting Information). No positive environmental samples were detected from the company $B$ (the fast food provider). As listed in Table 1, the floor samples had the highest positive rate, $45.8 \%$, followed by air samples (15.0\%), and surface swabs (5.7\%). The traveler (confirmed COVID-19) had stayed in two different rooms. And for one room (Room-A),

Table 1. Analysis of SARS-CoV-2 in air, floor and surface swab samples from the hotel, hotel employee building, and the fast food provider (Company B). Detailed sample information is listed in Supporting Information (Table S2).

\begin{tabular}{llll}
\hline Analysis of SARS-CoV-2 & Air samples ( $=20)$ & Floor samples $(\mathrm{N}=24)$ & Surface swabs (N = 193) \\
\hline SARS-CoV-2 positive rate & $3 / 20(15.0 \%)$ & $11 / 24(45.8 \%)$ & $11 / 193(5.7 \%)$ \\
Estimated SARS-CoV-2 RNA level & $5640-7840$ & $8-3340($ AVG: 680) & $14-9800($ AVG: 1120$)$ \\
& SARS-CoV-2 RNA m ${ }^{-3}$ & SARS-CoV-2 RNA cm ${ }^{-2}$ & SARS-CoV-2 RNA cm ${ }^{-2}$ \\
\hline
\end{tabular}


there were positive surface swab samples, including pillowcase, quilt and the toilet floor drain; for another one (Room-B), the toilet pit was found to be positive. After the outbreak, SARS-CoV-2 RNA was also detected from ventilation duct swab of the quarantine hotel in Changping District in Beijing where the traveler was quarantined. The two hotel cleaners cleaned both of these two rooms (on Dec. 13 for Room-A, on Dec. 14 for Room-B), and on Dec. 14 after the cleaning they washed and spin-dried the hotel uniforms in the female washroom shown in Fig. 1(A). For Room $\# 10$, SARS-CoV-2 was detected on door handler, quilt surface, floor, window curtain, cell phone surface (having the highest viral load per unit of surface area), as well as corridor floor outside the room (Fig. 1(A); Table S2). However, no positive samples were detected from Room \#8 and Room \#5 where the two cleaners stayed, respectively. For these two rooms, they have windows facing outside. For the public spaces, both toilet floors were detected positive as depicted in Fig. 1(A), and one bathroom floor was also found positive. For the female public space, there were more positive samples as listed in Table S2 and Fig. 1(A). For the female wash room, faucet surface swab was also detected positive (164 copies $\mathrm{cm}^{-2}$ ) in addition to the floor. Particularly important, two air samples collected on Dec. 20 and 21 respectively from the female washroom without ventilation even after the disinfection (Fig. S3) were still detected positive for SARS-CoV-2 with an estimated concentration level of 5640-7840 SARS-CoV-2 RNA copies $\mathrm{m}^{-3}$ (Table 1). The two air samplings taken on Dec. 20, 21, respectively, more than 4 days since the quarantine of the two confirmed fast food employees in Room \#10, were found to contain SARS-CoV-2 RNA. The air samples consisted $20 \mathrm{~m}^{3}$ of air each from the female washroom. However, no positive air samples were detected in Room \#10, \#5, \#8. In addition, the air sample collected using a robotassisted sampler (File S1) from the employee building corridor was also detected negative. For these samples, no viability tests were performed. Further using Vero cell tests, no viable SARS-CoV-2 was detected for three air samples additionally collected from the female washroom on Dec 22. Nonetheless, one of the samples was still detected positive for the virus but with a decreased level (16 RNA copies $\mathrm{m}^{-3}$ ). A surface swab from the employee building stairs (Fig. 1(A)) was detected positive on Dec 17. The employee building had an average temperatures of $14.2-18.9^{\circ} \mathrm{C}$ and 9.7$32.4 \%$ relative humidity. There is a connecting walking corridor between the Hotel and the employee building. Overall, the floor samples had SARS-CoV-2 RNA level of 8-3340 (AVG: 680) copies $\mathrm{m}^{-3}$, and the surface swabs had a corresponding level of 14-9800 (AVG: 1120) SARS-CoV-2 RNA copies $\mathrm{m}^{-3}$ (Table 1 ).

However, how the two employees (COVID-19 patients) from Room \#10 contracted the virus remained a mystery since epidemiological and surveillance data revealed that the traveler did not have any direct contacts with the fast food employees. All other people in the employee building were tested negative with SARS-CoV-2. During the outbreak, not all the 37 people stayed in the employee building. Viral next generation sequence analysis (full genome sequences from three COVID-19 cases and two environmental samples in this work) provided by Beijing CDC revealed that all SARS-CoV-2 virons collected from three patients belonged to the same lineage $20 B$, and shared a nucleic acid identity of $99.92 \%$ to $99.93 \%$ with a reference strain (MN908947.3) (Fig. 2). Nonetheless, a total of 17 amino acid substitutions were found among five full viral genomes, including ORF1a:C506Y, ORF1a:L890F, ORF1a:D1036E, ORF1a:N2201Y, ORF1a:T2202S, ORF1b:P314L, ORF1b:S1023G, ORF1b:P1452L, ORF3a:T223I, ORF6:F2S, ORF8:A65G, S:T95I, S:D614G, S:A688S, N:N8T, N:R203K and N:G204R (Table S3). The two environmental samples had higher genome similarity with one fast food employee than the other one. Accordingly, it can be reasoned that these two fast food employees contracted the virus from the contaminated environments such as surfaces and air in the employee building. The hotel cleaners washed their hands and hotel uniforms using the laundry inside the female washroom after cleaning the rooms occupied by the traveler. It is possible that SARS-CoV-2 was attached onto their working clothes which have been spin-dried after the washing. The process might have generated a large amount of aerosols containing the SARS-COV-2. However, surface swabs from the washer and drier were all detected negative for SARS-CoV-2. On the other hand, the two fast food employees could have contracted COVID-19 by touching the surfaces of handrail of the employee building stairs and the faucet, or through inhaling airborne viruses in the female washroom. The virus in the air seemed to have remained airborne for more than at least 4 days since the transport of the secondary COVID-19 cases to a local hospital for treatments on Dec. 17 and 18, 2020, respectively. Nonetheless, airborne viruses in the washroom could be possibly produced by the two confirmed fast food 


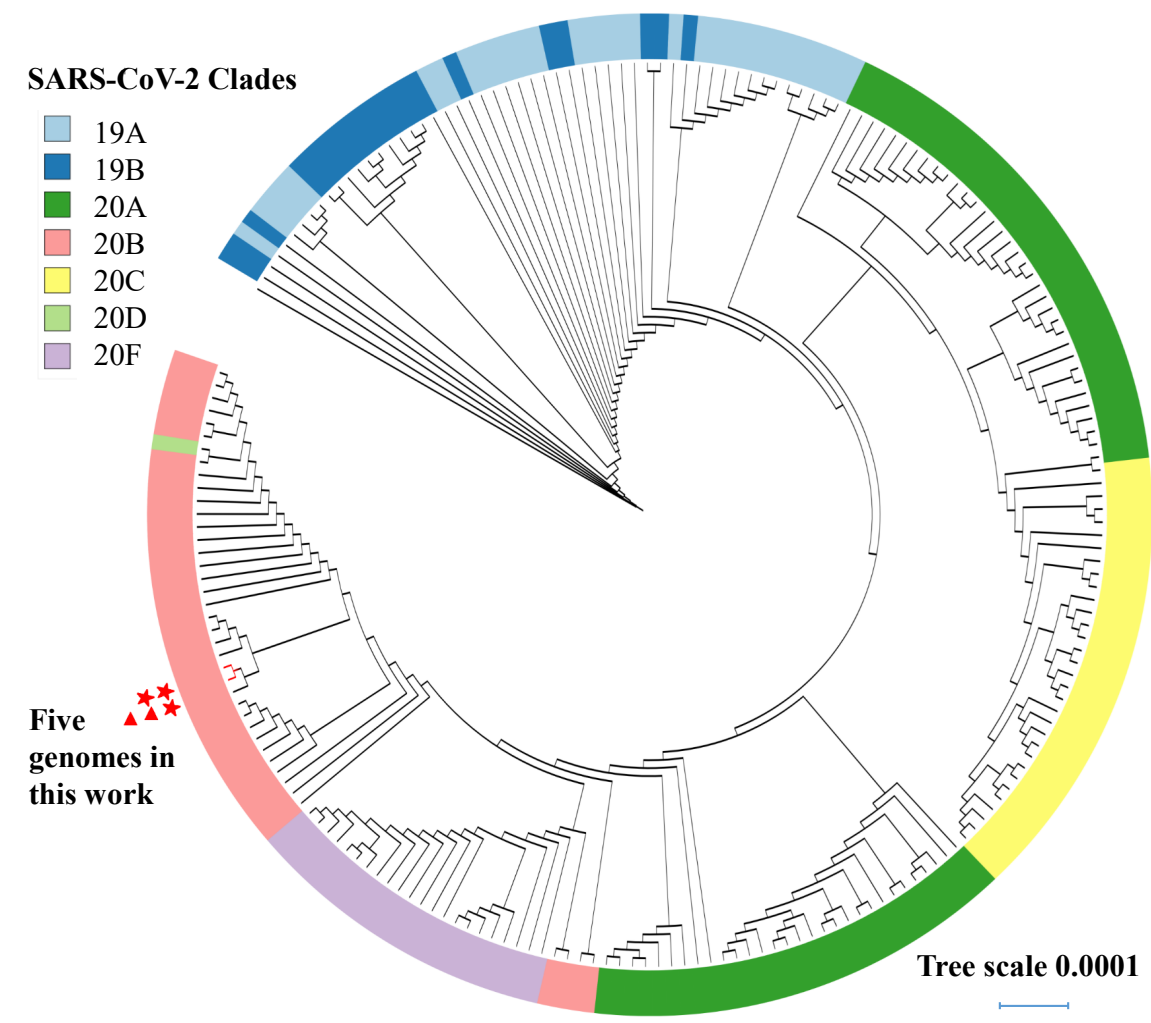

Fig. 2. Phylogenetic tree of SARS-CoV-2 in three reported COVID-19 cases and two environmental samples in this work. The tree was constructed by the $\mathrm{N}$-J method using the HKY model with bootstrap values determined by 1000 replicates (Supporting Information). The viruses detected in three COVID-19 cases were indicated by asterisks in the figure and their genome sequences were deposited to GISAID database. The genomes from two environmental samples were indicated by triangles.

employees (secondary cases) through breathing, coughing, or talking before their transport. Breath-borne particles once exhaled evaporate very fast, and they should be very small in size. Since the washroom without windows was not ventilated, and was in complete lockdown, thus having no resuspension, the collected viral particles should be primarily from the air, not from the floor. Nonetheless, we cannot eliminate some resuspension when placing the sampler in the washroom for sampling. Initially, the fast food employees may have been infected by inhaling the airborne SARS-CoV-2 produced by the cleaners during their activities in the room. From epidemiological and surveillance data, one of the fast food employees at least spent 10 minutes per day in the washroom during the outbreak period (Dec. 13-15, 2020), and shared similar workbreak-time frame with one of the cleaners in the employee building. By estimate, the employee could have inhaled at least 1600 SARS-CoV-2 particles assuming an average breathing rate of $12 \mathrm{~L} \mathrm{~min}^{-1}$ (10-20 breaths per min) (Ahmadi et al., 2020; Russo et al., 2017) before developing an infection based on the concentration data measured on Dec. 20, and 21 as listed in Table 1. However, this does not exclude higher levels of viruses at the earlier times. Likewise, it was also possible that the secondary cases could contract the virus from the faucet that was detected positive for the virus in the female washroom. The faucet might have been contaminated by the two hotel cleaners after cleaning the hotel rooms used by the traveler in this outbreak. And the viral level was estimated to be 164 RNA copies $\mathrm{m}^{-2}$ for the faucet on Dec. 17, and decreased to 48 copies $\mathrm{cm}^{-2}$ on the evening. Likewise, it could be higher during the earlier time, i.e., before the employee possibly contracted from it. Another possibility is that the two employees inhaled the re-suspended SARS-CoV-2 left by the cleaners via clothing or hairs from the floor of the female washroom (up to 3280 SARS-CoV-2 RNA cm${ }^{-2}$ ). It was shown that SARS-CoV-2 can remain viable in the air for at least $3 \mathrm{~h}$ and up to $72 \mathrm{~h}$ on surfaces (van Doremalen et al., 2020). Other people in the employee building were either absent from the environment or not exposed to a 
sufficient amount of infectious viruses due to a brief exposure during the outbreak. On the other hand, other hotel employees might not use the washroom and toilet facilities in the employee building as the hygiene conditions are not favorable compared to those freely available in the hotel. The data gathered from this work imply that an airborne SARS-CoV-2 infection might require that viruses are not aged in the air for so long. In other studies, those airborne viruses tested viable or non-viable using in vitro assay may not represent the same infectivity for cells in the human body. Here, viability tests showed that no viable SARS-CoV-2 was detected after aging for 5 days in the air. The results from this work indicate that some commonly touched surfaces of public utilities could be a hot spot for transmitting the COVID-19. On the other hand, in semi-enclosed space airborne transmission of the COVID-19 should be also given a particular attention.

There is a growing body of evidences for airborne transmission of COVID-19 (Ma et al., 2020; Lednicky et al., 2020; Azimi et al., 2021; Miller et al., 2020; Shen et al., 2020; Prather et al., 2020a, b; Hu et al., 2020). All the superspreading events (Azimi et al., 2021; Miller et al., 2020; Shen et al., 2020) as reported indicated that aerosol transmission of COVID-19 played a role. Lednicky et al. (2021) recovered infectious SARs-CoV-2 particles up to $3.4 \times 10^{4}$ RNA copies $\mathrm{m}^{-3}$ from air collected using a sampler at a flow rate of $9 \mathrm{~L} \mathrm{~min}^{-1}$ for $135 \mathrm{~min}$ from a passenger car. In another work, Habibi et al. (2021) reported a SARS-CoV-2 concentration level of 12-43 copies $\mathrm{m}^{-3}$ using a sampler operated at $30 \mathrm{~L} \mathrm{~min}^{-1}$ for $2 \mathrm{~h}$ in the patient waiting area for COVID-test. Here, we found SARS-CoV-2 have remained airborne with a level of more than 7000 RNA copies $\mathrm{m}^{-3}$ for at least 4 days in a closed space without ventilation. Using particle settling equation, those particles carrying SARS-CoV-2 were at least smaller than $0.4 \mu \mathrm{m}$ at a velocity of $6.37 \mu \mathrm{m} \mathrm{s}^{-1}$ given the height $(2.2 \mathrm{~m})$ of the washroom. The air samples were collected twice from the washroom, and all of them were found positive (5640-7840 SARS-CoV-2 RNA m${ }^{-3}$ ). If there was ventilation for this room, the airborne viral particles could be diluted away to substantially reduce the viral aerosol level. Thus, our finding suggests that proper ventilation is very important in public spaces, especially for those high-risk areas, to help mitigate the viral exposure. The investigation from this work also reveals a flaw in current quarantine practice. The traveler was tested negative using RT-PCR test with throat swabs before the quarantine discharge on Dec. 12, 2020. However, after the outbreak the air ventilation duct in his quarantine hotel room before the discharge was detected positive. The false negative PCR test using throat swab subsequently led to the COVID-19 outbreak in the hotel as described. Accordingly, additional tests using different samples or different methods should be explored to guard the public safety when discharging those overseas travelers or those already in quarantine. Among other strategies, exhaled breath from COVID-19 patients was found to contain SARS-CoV-2 even they were ready for hospital discharge (Zhou et al., 2020). Exhaled breath is a lot easier to collect and induces less discomfort, and it could serve as a supplement sample to re-assure the test from throat swab RT-PCR. On another front, breath-borne volatile organic compounds (VOCs) were also used to screen COVID-19 through machine learning analysis (Chen et al., 2020; Grassin-Delyle et al., 2020; Shan et al., 2020). Additionally, environmental samples collected from the rooms where the to-be-discharged subjects stayed can be also tested for SARS-CoV-2 to further assure the validity of human sample tests. These different types of samples could provide additional checks for the RT-PCR tests adopted for COVID-19 screening. In addition to using different sample types, different virus detection technologies could be also employed to enhance the screening, especially those with low detection limits such as digital PCR (Liu et al., 2020; Zhou et al., 2021) and electrochemical method (Chaibun et al., 2021). For countries with zero local COVID-19 case, two possible SARS-CoV-2 sources are imported products and COVID-19 patients. For the latter, it is relatively easy to manage and control, however quarantine discharge should be carefully carried out. After the outbreak, the Chinese government applies additional 7 days' self-home health monitoring with restricted social activities. With respect to imported products including seafood, disinfection for the product surfaces as well as the package itself plays a vital role in preventing the potential SARS-CoV-2 infection and transmission.

\section{CONCLUSIONS}

Based on environmental, epidemiological tracing, surveillance video and sequence data, we concluded that the infected employees contracted the viable virus from contaminated environments. 
However, we do not know whether they were infected by inhaling the virus from the air or touching the faucet in the washroom or the building stair handrail. For low or without ventilation space, airborne SARS-CoV-2 could remain airborne for a prolonged time, thus presenting an exposure risk. Our work is believed to be among the earliest studies to report direct evidence for environmental transmission of COVID-19. In the future, time-resolved viability of airborne SARSCoV-2 and their influencing factors should be investigated. Our results imply that future efforts are greatly needed to closely monitor environmental air and surface safety; and correspondingly carry out disinfections in public spaces that operate with low ventilation and poor hygiene. Genetic sequence data can help trace the transmission route.

\section{ACKNOWLEDGMENTS}

This research was supported by a National Natural Science Foundation of China (NSFC) grant (22040101) (PI : M Yao) and by the NSFC Distinguished Young Scholars Fund Awarded to M. Yao (21725701), and also by a grant from Guangzhou Laboratory (EKPG21-02).

\section{DISCLAIMER}

M.Y. and J.M. contributed to the study design, and J.M. managed the epidemiology work. X.Q. and X.L. contributed to sample collection and experiments. X.L. was responsible for coordinating the air sampler and prepared draft figures. Y.P. contributed to the virus sequencing. T.T. and L.S. contributed to SARS-CoV-2 analysis from the samples collected. Y.Z., Z.L., W.L., and Z.Z. contributed to sample collection and epidemiological tracing. Q.W. coordinated the sample transport and analysis. M.Y. and X.L. wrote the manuscript draft, and all authors revised the manuscript. All authors reviewed and approved the final version of the report. All authors contributed to data analysis, data interpretation, figure preparation and literature search. The authors declare no competing interests. All data are available in the main text or the supplementary materials.

\section{SUPPLEMENTARY MATERIAL}

Supplementary material for this article can be found in the online version at https://doi. org/10.4209/aaqr.210131

\section{REFERENCES}

Ahmadi, M., Zuber, M., Khader, S.A. (2020). Airflow simulation inside the nasal cavity. MJMIE 4, 21-25. https://doi.org/10.33544/mjmie.v4i1.122

Azimi, P., Keshavarz, Z., Laurent, J.G.C., Stephens, B., Allen, J.G. (2021). Mechanistic transmission modeling of COVID-19 on the Diamond Princess cruise ship demonstrates the importance of aerosol transmission. PNAS 118, e2015482118. https://doi.org/10.1073/pnas.2015482118

Chaibun, T., Puenpa, J., Ngamdee, T., Boonapatcharoen, N., Athamanolap, P., O’Mullane, A.P., Vongpunsawad, S., Poovorawan, Y., Lee, S.Y., Lertanantawong, B. (2021). Rapid electrochemical detection of coronavirus SARS-CoV-2. Nature Commun. 12, 802. https://doi.org/10.1038/s41467021-21121-7

Chen, H., Qi, X., Ma, J., Zhang, C., Feng, H., Yao, M. (2020). Breath-borne VOC biomarkers for COVID-19. medRxiv. https://doi.org/10.1101/2020.06.21.20136523

Grassin-Delyle, S., Roquencourt, C., Moine, P., Saffroy, G., Carn, S., Heming, N., Fleuriet, J., Salvator, H., Naline, E., Couderc, L.J., Devillier, P., Thévenot, E.A., Annane, D. (2020). Metabolomics of exhaled breath in critically ill COVID-19 patients: A pilot study. EBioMedicine 63, 103154. https://doi.org/10.1016/j.ebiom.2020.103154

Guo, Z.D., Wang, Z.Y., Zhang, S.F., Li, X., Li, L., Li, C., Cui, Y., Fu, R.B., Dong, Y.Z., Chi, X.Y., Zhang, M.Y., Liu, K., Cao, C., Liu, B., Zhang, K., Gao, Y.W., Lu, B., Chen, W. (2020). Aerosol and surface distribution of severe acute respiratory syndrome coronavirus 2 in hospital wards, Wuhan, China, 2020. Emerg. Infect. Dis. 26, 1586-1591. https://doi.org/10.3201/eid2607.200885 
Hu, J., Lei, C., Chen, Z., Liu, W., Hu, X., Pei, R., Su, Z., Deng, F., Huang, Y., Sun, X., Cao, J., Guan, W. (2020). Distribution of airborne SARS-CoV-2 and possible aerosol transmission in Wuhan hospitals, China. Natl. Sci. Rev. 7, 1865-1867. https://doi.org/10.1093/nsr/nwaa250

Lednicky, J.A., Lauzard, M., Fan, Z.H., Jutla, A., Tilly, T.B., Gangwar, M., Usmani, M., Shankar, S.N., Mohamed, K., Eiguren-Fernandez, A., Stephenson, C.J., Alam, M.M., Elbadry, M.A., Loeb, J.C., Subramaniam, K., Waltzek, T.B., Cherabuddi, K., Morris, Jr. J.G., Wu, C.Y. (2020). Viable SARSCoV-2 in the air of a hospital room with COVID-19 patients. Int. J. Infect. Dis. 100, 476-482. https://doi.org/10.1016/j.ijid.2020.09.025

Li, X., Chen, H., Qi, X., Peng, Y., Zhou, L., Ma, J., Yao, M. (2021), A robot assisted high-flow portable cyclone sampler for bacterial and SARS-CoV-2 Aerosols. Aerosol Air Qual. Res. 21, 210130. 210130. https://doi.org/10.4209/aaqr.210130

Liu, Y., Ning, Z., Chen, Y., Guo, M., Liu, Y., Gali, N. K., Sun, L., Duan, Y., Cai, J., Westerdahl, D., Liu, X., Xu, K., Ho, K., Kan, H., Fu, Q., Lan, K. (2020). Aerodynamic analysis of SARS-CoV-2 in two Wuhan hospitals. Nature 582, 557-560. https://doi.org/10.1038/s41586-020-2271-3

Ma, J., Qi, X., Chen, H., Li, X., Zhang, Z., Wang, H., Sun, L., Zhang, L., Guo, J., Morawska, L., Grinshpun, S.A., Biswas, P., Flagan, R.C., Yao, M. (2020). COVID-19 patients in earlier stages exhaled millions of SARS-CoV-2 per hour. Clin. Infect. Dis. ciaa1283. https://doi.org/10.1093/c id/ciaa1283

Miller, S.L., Nazaroff, W.W., Jimenez, J.L., Boerstra, A., Buonanno, G., Dancer, S.J., Kurnitski, J., Marr, L.C., Morawska, L., Noakes, C. (2020). Transmission of SARS-CoV-2 by inhalation of respiratory aerosol in the Skagit Valley Chorale superspreading event. Indoor Air 31, 314-323. https://doi.org/10.1111/ina.12751

Ong, S.W.X., Tan, Y.K., Chia, P.Y., Lee, T.H., Ng, O.T., Wong, M.S.Y., Marimuthu, K. (2020). Air, surface environmental, and personal protective equipment contamination by severe acute respiratory syndrome coronavirus 2 (SARS-CoV-2) from a symptomatic patient. JAMA 323, 1610-1612. https://doi.org/10.1001/jama.2020.3227

Prather, K.A., Marr, L.C., Schooley, R.T., McDiarmid, M.A., Wilson, M.E., Milton, D.K. (2020a). Airborne transmission of SARS-CoV-2. Science 370, 303-304. https://doi.org/10.1126/science. abf0521

Prather, K.A., Wang, C.C., Schooley, R.T. (2020b). Reducing transmission of SARS-CoV-2. Science 368, 1422-1424. https://doi.org/10.1126/science.abc6197

Russo, M.A., Santarelli, D.M., O’Rourke, D. (2017). The physiological effects of slow breathing in the healthy human. Breathe 13, 298-309. https://doi.org/10.1183/20734735.009817

Santarpia, J.L., Rivera, D.N., Herrera, V.L., Morwitzer, M.J., Creager, H.M., Santarpia, G.W., Crown, K.K., Brett-Major, D.M., Schnaubelt, E.R., Broadhurst, M.J., Lawler, J.V., Reid, St. P., Lowe, J.J. (2020). Aerosol and surface contamination of SARS-CoV-2 observed in quarantine and isolation care. Sci. Rep. 10, 12732. https://doi.org/10.1038/s41598-020-69286-3

Shan, B., Broza, Y.Y., Li, W., Wang, Y., Wu, S., Liu, Z., Wang, J., Gui, S., Wang, L., Zhang, Z., Liu, W., Zhou, S., Jin, W., Zhang, Q., Hu, D., Lin, L., Zhang, Q., Li, W., Wang, J., Liu, H., Pan, Y., Haick, H. (2020). Multiplexed nanomaterial-based sensor array for detection of COVID-19 in exhaled breath. ACS Nano 14, 12125-12132. https://doi.org/10.1021/acsnano.0c05657

Shen, Y., Li, C., Dong, H., Wang, Z., Martinez, L., Sun, Z., Handel, A., Chen, Z., Chen, E., Ebell, M. H., Wang, F., Yi, B., Wang, H., Wang, X., Wang, A., Chen, B., Qi, Y., Liang, L., Li, Y., Ling, F., et al. (2020). Community outbreak investigation of SARS-CoV-2 transmission among bus riders in eastern China. JAMA Intern. Med. 180, 1665-1671. https://doi.org/10.1001/jamainternmed.2 020.5225

van Doremalen, N., Bushmaker, T., Morris, D.H., Holbrook, M.G., Gamble, A., Williamson, B.N., Tamin, A., Harcourt, J.L., Thornburg, N.J., Gerber, S.I., Lloyd-Smith, J.O., de Wit, E., Munster, V.J. (2020). Aerosol and surface stability of SARS-CoV-2 as compared with SARS-CoV-1. N. Engl. J. Med. 382, 1564-1567. https://doi.org/10.1056/NEJMc2004973

Zhou, L., Yao, M., Zhang, X., Hu, B., Li, X., Chen, H., Zhang, L., Liu, Y., Du, M., Sun, B., Jiang, Y., Zhou, K., Hong, J., Yu, N., Ding, Z., Xu, Y., Hu, M., Morawska, L., Grinshpun, S.A., Biswas, P., et al. (2020). Breath-, air-and surface-borne SARS-CoV-2 in hospitals. J. Aerosol Sci. 152, 105693. https://doi.org/10.1016/j.jaerosci.2020.105693 